\title{
ESTUDIOS HISTOLÓGICOS DE LA EMBRIOGÉNESIS SOMÁTICA: UNA NECESIDAD PARA EL CONOCIMIENTO DE LOS PROCESOS BIOTECNOLÓGICOS Y LA CONSERVACIÓN DE LA BIODIVERSIDAD EN EL C ULTIVO DEL BONIATO
(IIPOMOEA BATATAS (L.) LAM.)
}

\section{O. S. González Paneque ${ }^{I}$, O. Sam Morejón ${ }^{2}$, M. Hernández Espinosa ${ }^{3}$, M. J. Coronado y J. J. Silva Pupo ${ }^{l}$}

1 Centro de Estudios de Biotecnologla Vegetal, Facuitad de, Ciencias Acricolas, Universudad de Granma, Apdo. 21, Bayamo, Granma, Cuba, e-mall: ogpanequegudg.co.cu

2 Departamento de. Fisiologia Vegetal. Instituto Nacional de Cienclas Agricolas.

3 Depajtramento de Genítica y Mejoramiento de las Plantas, Instituto Nacional de Cienclas Agricolas, Gaveta Postal. 1, San José de las Lajas, La Habana, Cuba.

4 Centuo de Investicaciones Cientificas, Consejo Superior de Investigaciones Cientificas, Madrid, Espakia.

\section{INTRODUCCIÓN}

El cultiwo del boniato (Ipomeer batatas (L, LamL) offece diversas ventajas económicas para muchos países y en especial para Cuba, ya que se puede emplear en la alimentación humana y animal, así como en la industria.

Las técnicas de cultivo de tejidos son utilizadas para una tápida propagación de plantas, como una fuente importante de información genética en células vegetales $y$ regeneración de algunas ca- racteristicas (MAXIMOTA at al., 2002; HITA et al., 2003); siendo necesario conocer los ispectos de diferenciación celular y la histogénesis para podes entender mejor la organogénesis (VIEIRA \& ESQUIBEL, 1998). La embriogénesis somática es altamente dependiente de la especie, el genotipo. el estado fisiológico de la planta donante, las condiciones de incubación, la composición del medio de cultivo, el estado de dexartollo del explante y la técnica de cultivo in vitro que se aplique (RISUENO, 2000). 
En este sentido, la histogénesis ocupa un papel preponderante porque permite conocer la composición celular de los tejidos con estructuras organizadas; todo lo cual se relleja en un mejor conocimiento de $\mathrm{t}$ biodiversidad de los diferentes ecosistemas favoreciendo el estudio de las condiciones medioambientales.

Dentro de los procesos biotecnológicos, la $\mathrm{cm}$ briogénesis somática es un medio de micropropagación que explota las totipotencialidades de las células vegetales, siendo empleada dentro de los métodos de propagación por su alto indice de multiplicación (TESTILLANO es al, 2000).

En el cultivo del boniato con el empleo de la embrogénesis somática se abren nuevax áreas a la investigación científica y al estudio de la biodiversidad, representando una herramienta de gran utilidad para la multiplicación e introducción de nuevos clones. La utilización de la embriogénesis somática permite la obtención de un número elevado de plantas en corto tiempo y es de gran utilidad en los programas de multiplicación en diferentes cultivos de interés, en el boniato en particular constituye un aspecto de gran importancia en la agricultura moderna.

Para un mayor conocimiento y una mejor comprensión de los cambios estructurales que dan lugar a la embriogénesis somática, mediante la aplicación del cultivo in vitro, se ha hecho uso de las técnicas histológicas que han facilitado describir el proceso que conduce a un tejido a readquirir sus potencialidades embriogénicas y esto puede ser determinado para diferentes tejidos y plantas (RAMIREZ et al.. 2000).

Es por ello que, el objetivo del presente trabajo fue evaluar histológicamente el proceso de callogénesis y embriogénesis somática a partir de explantes de limbos foliares de boniato en el clon cubano INIVIT B 93-1.

\section{MATERIALES Y MÉTODOS}

El trabajo fue realizado en el Departamento de Fisiologia Vegetal del Instituto Nacional de Ciencias Agricoles (INCA) de La Hahana, en colaboración con el Centro de Investigazciones Biológicas (CIB) del Consejo Superior de Investigaciones Cientificas (CSIC), Madrid, España. Se recolectaron raíces tuberosas pertenecientes al clon cubano INIVIT B 93-1 y se efectuaron cortes histológicos en explantes de limbo foliar, callos, callos con estructuras embriogénicas y embriones somáticos en diferentes etapas de desarrollo.

En todo momento se empleó d medio de cultivo propuesto por MURASHIGE \& SKOOG (1962), suplementado con Mioinositol (100 mg. $\left.\mathrm{L}^{-1}\right)$. Tiamina (1 mg. $\left.\mathrm{L}^{-1}\right)$. Vitaminas MS (10.0 ml. $\left.\mathrm{L}^{-1}\right)$, Sacarosa $(3 \%)$ y Gelrite $(0.2 \%)$. Los reguladores del crecimiento fueron incorporados al medio de cultivo en dependencia del objetivo planteado en cada experimento, $\mathrm{d} \mathrm{pH}$ del medio fue ajustado a $5.8 \pm$ 0.01 en todos los casos, previo a la adición del agente solidificante $y$ esterilizados en autoclave a $121^{\circ} \mathrm{C}(1.2$ $\mathrm{Kgf} / \mathrm{cm}^{2}$ de presión) durante 20 minutos.

Para el estudio histológico se tomó una porción de $2 \mathrm{~mm}^{2}$ para los explantes de limbo foliar y de 2 mm' para el resto de los materiales estudiados con tres repeticiones en cada muestreo. Las muestras fueron fijadas en formaldehido $(4 \%)$ en tampón fosfato a $\mathrm{pH} 7.1$, durante veinticuatro horas a $4^{\circ} \mathrm{C}$. postetiormente se lavaron tres veces con PBS (solución fosfo-salina tamponada) durante diez minutos. se deshidrataron en soluciones crecientes de etanol y se pasaron a óxido de propilenoletanol hasta quedar en óxido de propileno puro para realizar $\mathrm{t}$ infiltración e inclusión en Epon, según la técnica empleada por RISUENO (2000).

Los cortes semifinos de $1 \mu \mathrm{m}$ de grosor se obtuvieron con cuchillas de vidrio en un ultramicrótomo LKB Nova (Upsala, Sweden). La tinción se realizó con azul de toluidina $(0.01 \%)$ en agua, las secciones fueron fotografiadas en un microscopio Olympus con cámara digital acoplada.

Para los estudios histológicos se tuvieron en cuenta las siguientes etapas:

Formación del callo con estructuras embriogénicas. Se seleccionaron explantes de limbos foliares $\left(1.0 \mathrm{~cm}^{2}\right)$, desinfectados con hipoclorito de sodio (10\%), durante 15 minutos y sembrados en el medio de cultivo propuesto por MURASHIGE \& SKOOG (MS) (1962), vitaminas MS (10 mg $\left.\mathrm{L}^{-1}\right)$, mioinositol (100 $\left.\mathrm{mg} \mathrm{L}^{-1}\right)$, sacarosa (306), Gelrite $(0.2 \%), 2,4-\mathrm{D}\left(0.50 \mathrm{mg} \mathrm{L}^{-1}\right)$ y $6-\mathrm{BAP}(0.25$ mg $\left.\mathrm{L}^{-1}\right)$, mantenidos en la oxcuridad permanente 
durante treinta dias. Las muestras fueron fijadas a los tres, seis, nueve, catorce y veintiún dias después de la siembra, y los callos no embriogénicos $y$ con estructuras embriogénicas a los treinta dias, para su posterior procesado para la inclusión en resina y obtención de cortes semifinos.

\section{Formación de los embriones somáticos.}

Se empleó el medio anteriormente mencionado conteniendo además tiamina $\left(1 \mathrm{mg} \mathrm{L} \mathrm{L}^{-1}\right.$ ) y el 2,4-D a una concentración de $0.2 \mathrm{mg} \mathrm{L}^{-1}$, con un fotoperiodo de 16 horas luz y 8 oscuridad durante treinta dias; transcurtido este tiempo se lex realizaron los cortes histológgicos.

\section{Caracterización de los embriones somáticos.}

Se emplés el medio de cultivo anteriormente mencionado con $\mathrm{ABA}\left(1.0 \mathrm{mg} \mathrm{L}^{-1}\right)$ y se realizaron los cortes a los embriones somáticos en las etapas: globular, corazón, torpedo y cotiledonal.

\section{RESULTADOS Y DISCUSIÓN}

Formación del callo con estructurnas embriogénicas.

En secciones transversales realizadas al limbo foliar, se observó la epidermis (adaxial y abaxial) y el paténquima clotofilico bien diferenciado en empalizada y el lagunar o esponjoso (Figura 1A). caracteristica de estas plantas que las distingue dentro del ecosistema, permitiendo la identificación y conservación de la biodiversidad.

A partir de los tres dias de sembrado el explante, ocurrió la inducción del callo donde las estructuras del limbo foliar se mantuvieron intactas y se observó la proliferación de células indiferenciadas en el parénquima esponjoso que dieron lugar a la callogénesis, originándose callos de cicatrización en los bordes del explante cercanes a la región del haz vascular y una disminución de la intensidad de la coloración verde.

A los seis dias se observó un mayor engrosamiento del callo, dando lugar a un callo endógeno. El incremento en todas direcciones originó que se hiciera notable y luego se proyectó hacia el exterior a través de la epidermis; después, de los siete dias se observó la aparición de pequeños callos de color amarillo-crema en los bordes del explante y se observó la presencia de agrupaciones celulares similares a las que forman las células embriogénicas meristemáticas. No cabe duda que en este periodo el callo comenzó una etapa de división con una rápida multiplicación celular; todo lo cual coincidió con lo planteado por Gonzílez y Ferter (1996), quienes demostraron que a partir de los siete dias después de la siembra, se obserwó en el callo de cicatrización y en las células meristemáticas divisiones periclinales del callo endógeno que a partir de los doce dís se encontraba ocupando toda la superficie del explante.

A los veintiún días se observó el desarrollo pleno del callo de color crema-amarillo, con estructuras nodulares formado por células pequeñas $y$ abundantes. y a los treinta dias presentó una apariencia homogénea, predominando las celulas meristemáticas y textura friable (Figura 1B), presentándose una total decoloración del explante cubierto por el callo en su totalidad. Aunque se puede encontrar una sección del callo no embriogénico y se pudo observar que éste se caracterizó por presentar en su mayoria células alargadas, parénquimaticas (Figura 1B).

Conjuntamente con las células embriogénicas también se observaron células de tipo no embriogénicas altamente diferenciadas y vacuoladas, demostrándose que en un mismo callo pueden existir células con capacidad embriogénica y células no embriogénicas, y la formación de un tipo de callo 4 otro, depende del explante empleado y la formación de los proembriones puede ser influido por el genotipo como indicaron RIVAL (2000) y GOH ot all. (2001).

Se ha demostrado que las células embriogénicas proceden de las células meristemáticas y el aumento en el número de éstas se debe casi enteramente a la división repetida en tejidos meristemáticos expecificos que se hallan sólo en regiones limitadas y estaín formados por células permanenternente embrionatias según señalaton LAPARRA ef all. \{1997\}.

La capacidad morfogénica de algunos tejudos puede no tomarse en consideración según lo planteado por CONCEPCIÓN et al (2003), debido a la asociación de estos con tejidos diferenciados que estin dentro de un sistema organizado y todo ello debe tenerse presente en la identificación del material vegetal $y$ el manejo de la biodiversidad a partir de los estudios histolóngicas realizados. 

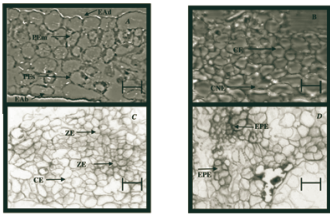

Figura 1. Cortes histológicos del limbo foliar y de callos de boniato del clon INIVIT B 93-1.

(A): Secciones transversales del limbo foliar tomadas al momento de realizar la siembra. (B): Callo con 30 dias de formado $y$ con predominio de células pequeñas y abundantes. (C): Sección transversal de un callo con zonzas embriogénicas después de los cinco dias del subcultivo. (D): Sección transversal de un callo con estructurns proem. briogénicas. Barras en las fotos: (A) $-100 \mu \mathrm{m},(B)=150 \mu \mathrm{m},(C)$ y (D) $-2000 \mu \mathrm{m}$.

Leyenda. EAd: Epodermis Adasial. EAb: Fpidermb Abaxial. PEms Parenquima en Eumpalizada. PEs: Parenquima Espanjoso CE: CAlulas Embriogtaicas. CNE: Celulas No Embeicogenicas. ZE: Zona Embriogénici. EPE: Esrrucrura Proembriogénica.

\section{Formación de los embriones somáticos.}

Después de los cinco días de colocados los callos en el medio de cultivo se observó el desarrollo de zonas embriogénicas (Figura 1C), que posteriormente dieron inicio a la formación de estructuras proembriogénicas (Figura 1D). En las zonas meristemáticas ocurren frecuentemente divisiones anticlinales $y$ periclinales de las células y se han tealizado observaciones donde se demuestra que en la organización incipiente de zonas embriogénicas se puede apreciar la presencia de diferentes tipos celulares (Risuefio, 2000).

Pasados veinte días se observó una elevada presencia de embriones somáticos, principalmente en aquellas partes ubicadas en el centro y bordes del callo, los cuales se caracterizaron por presentar una morfología similar a los embriones cigóticos. A los veinticinco dias, se pudo observar la emergencia de los embriones y en muchos casos se vio la presencia de estos en una misma wona del callo.
Las observaciones histológicas realizadas, al igual que el posterior desartollo morfológico bipolar de los embriones somáticos al ser colocidos en el medio de germinación, demostró la naturaleza embriogénica del proceso estudiado $y$ esto posibilita garantizar la prospección del material vegetal a gran excala, contribuyendo con las ecosistemas vegetales $y$ la biodiversidad a nivel mundial.

\section{Caracterización de los embriones somatricos.}

Las secciones longitudinales de los embriones somáticos mostraron b naturaleza bipolar propia de los mismos y L posterior diferenciación en embriones somáticos independientes. Se pudo observar la gran variación existente en cuanto a forma, tamańo y apariencia de los embriones somáticos. Lo anterior demuestra que es necesario realizar estudios histológicos detallados desde d inicio del callo hasta la completa formación $y$ desarrollo de los embriones somáticos, lo que puede ser usado para conocer ef 


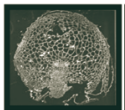

Globular (A)

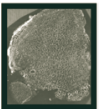

Corazín (B)

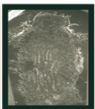

Torpedo (C)

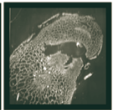

Cotiledonal (D)

Figura 2. Secciones histológicas de los embriones somáricas en diferentes exapas de desarrollo.

tiempo de subcultivo de los mismos, optimizando la efectividad de las condiciones fisicas y quimicas de los cultivos durante la embriogénesis somática y esto corrobora lo planteado por algunos autores al referirse a la evolución histolóngica del desarrollo de los callos con estructuras embriogénicas (Concepción et al., 2003).

Al estudiar el embrión en la etapa cotiledonal se observó que este presentó un meristemo apical y un meristemo radical conectados vascularmente; estas estructuras se formaron simultáneamente pasando los embriones somátions por diferentes etapas de desartollo, entre los cuales se encuentran: globular, acorazonado, torpedo y cotiledonal (Figura 2).

Aunque todas las células de un organismo son consideradas del mismo genotipo, no todas responden a la formación de embriones somáticos de igual manera, debido a que solarnente ciertas cellulas parecen estar aptas a tesponder a la embriogénesis somática dado la influencia de los reguladores del crecimiento y una vez formadas las células embriogénicas, no todas están simultáneamente listas desde el punto de vista fisiológico para expresar su totipotencia, aún en un medio favorable para su desartollo.

\section{CONCLUSIONES}

La formación del allo se produjo a partir de las células del parénquima perivascular que posteriormente surgieron las estructuras embriogénicas, las cuales se dividieron activamente tomando un mayor desarrollo que ocasionó el rompimiento de la epidermis para asi permitir la emergencia de las células del callo y la aparición del callo exógeno donde posteriormente aparecieron los embriones somáticos caracterizados por presentar una morfologia totalmente normal.

Con el presente trabajo se puede garantizar la multiplicación acelerada y en corto tiempo de plantas de interés y de aquellas en las que existen peligros de extinción, lo cual garantiza que no se produzcan pérdidas de la biodiversidad vegetal y se desarrolla una cultura sobre el uso de los recursos fitogenéticos valiosos para el hombre; unido a esto se puede contribuir con la conservación del material vegetal, garantizando gran número de tecursos beneficiosos para el bienestar del hombre. siempre que los mismos se manipulen con la mayos efectividad posible.

\section{AGRADECIMIENTOS}

Lisbeth Saldinar Reynaldo, Mirtha López Machado y Michel Martinez Cruz del Instituto Nacional de Ciencias Agricolas de La Habana (INCA). Marlyn Valdés de la Cruz de la Facultad de Biologia de la Universidad de La Habana. Hildelisa Saralegui Boza det Jardin Botánico Nacional, La Habana.

\section{REFERENCIAS}

BUDIMIR, G. 2003. Developmental histology of organogenic and embryogenic tissue in Piced omorika culture. Brief Communication. Biologia Plantarum, 47 (3): 467.470.

CONCEPCIÓN, O., NAPPOLES, L.. TRUJLLO. R., PÉREZ, A. \& PERALTA, N. 2003. Regene- 
ración de brotes en hojas de Guayaba (Psidium guatjatu L.) propagadas in viro. Taller Internacional de Biotecnologgia Vegetal. (BioVeg 2003). Centto de Bioplantas. Ciego de Ávila. Cuba.

DIANGOU, J., HOCHER, V., FERREIÉRE, N., FULCHERI, C., MORARD, P., \& ALEMANNO, L. 2002. Histological and biochemical characterization of Thewbromat catas L. Endosperm during seed development. Seed Science Research, 12: $89-100$.

FARIAS, F.R. 2000. Cultivo in vitro de Anthurium schlechtendalii Kunth (Aniceate), especie silvestre del estado de Veracruz, México. Tesis de Maestria (Master en Biotecnologia de Plantas). Universidad Veracruzana. Facultad de Ciencias Biolóngicas y Agropectuarias. Veracruz. $119 \mathrm{p}$.

GOH, D., BON, M., ALIOTTI, F., ESCOUTE, J., FERREIRE, N. \& MONTEVVIS, O. 2001. In vitro somatic embryogenesis in two major rattan species: Calasus merrillis and Calanus subinermis. In vitro CELL. DEV. BIOL-PLANT, 37: $375-881$.

GONZAIEZ, M.E \& FERRER. M. 19\%6. Caracterización histológica de la callogénesis en Coffert arabica var. "Caturta" durante La embriogénesis somática. Resúmenes. Taller de Biotecnología Vegetal de las Provincias Orientales. P. 6. Cuba. HITA, O., GALLEGO, P., VIL.L.ALOBOS, N., LANAS, I., BLAZZQUEZ, A., MLARTIN, J.P., FERNÁNDEZ, J., MARTIN, L. \& GUERRA, H. 2003. Imptovement of somatic embryogenesis in Medicayo arborea. Plan Cell, Tissue and Oryan Gulture, $72(1)=13-18$.

LAPARRA, H., BRONNER, R. \& HAHNE, G. 1997. Histological analysis of somatic embryogenesis induced in leaf explants of Helianshus snithit Heiser. Protoplasm, 196: 1-11.
MAXIMOVA, S.N., AL EMANNO, L., YOUNG, A., FERRIERE, N., TRAORE, N. \& GUILTIMAN, M.J. 2002. Efficiency, genotypic variability, and cellular otigins of primary and secondary somatic embryogenesis of Theobroma catae L In Virro Cellular and Developmental Biology-Phint., 38 (3): 252-259.

MURASHIGE, T. \& F SKOOG. 1962. A revised medium for rapid growth and bionssays with tobacco tissue culture. Plysid Plantix., 15: 473-497.

RAMIREZ, C., TESTIL.LANO, P., PINTOS, B., MORENO, M., DOMENECH, J., GÓMEZ. A., MANZANERA, J., BUENO, M. \& RISUENO, M. 2000. Cellular characterization of microspore embryogenesis in anther culture of Qnerus suber. Biasechndogical Approunch for Utilizition of Gumetic Celts. Cost 824, Bled, Sloverial P. 1-5.

RISUENO, M. 2000. Microspore-derived embryogenesis from in vitro cultures of heat-stressed anthers of Catpsicsom annum involves a dedifferentiation followed by proliferation and further redifferentiation. Plant Development and $\mathrm{Nu}$ dear Organization. CSIC.

RIVAL, A. 2000. Somatic embryogenesis in oil palm. In: Jain, S., Gupta, R., Newton, R. (eds.). Somatic enónos in woody plant, Vol. 6. Dordrehit, Boston, London: Kluwer Acadernic Publishers. P. 249-290.

TESTILLANO, P., CORONADO, M., SEGUI, J., DOMENECH, J., GONZÁLEZ-MELENDI, P. RASHA, I. \& RISUENO, M. 2000. Defined nuclear changes accompany the reprogramming of the microspore to embryogenesis. Journal of Structurd Biology, 129: 223-232.

VIEIRA, R. \& ESQUIBEL, M.D. 1998. Histogenesis of callus from stem explants of lpomoen buttatas (L.) Lam. Leandra, (13): 45-55. 